\title{
Serum and salivary macrophage migration inhibitory factor in patients with oral squamous cell carcinoma
}

\author{
MARIANA BARBOSA DE SOUZA ${ }^{1,2}$, OTÁVIO ALBERTO CURIONI ${ }^{2,3}$, \\ JOSSI LEDO KANDA ${ }^{4}$ and MARCOS BRASILINO DE CARVALHO ${ }^{2,3}$
}

\author{
${ }^{1}$ Department of Radiology and Oncology, Medical School, University of São Paulo, São Paulo 01246903; \\ ${ }^{2}$ Laboratory of Molecular Biology and ${ }^{3}$ Department of Head and Neck Surgery and Otorhinolaryngology, \\ Heliópolis Hospital, São Paulo 04231030; ${ }^{4}$ Department of Head and Neck Surgery, Padre Anchieta Teaching Hospital, \\ ABC Medical School, São Bernardo do Campo 09715090, Brazil
}

Received January 28, 2014; Accepted July 1, 2014

DOI: $10.3892 / 01.2014 .2513$

\begin{abstract}
The overexpression of macrophage migration inhibitory factor (MIF) has been identified in a variety of tumors and the investigation of its molecular mechanisms in tumor progression is a key topic of research. The present study aimed to investigate MIF as a potential marker for disease control or recurrence, and to assess the association between serum and salivary MIF and the clinicopathological characteristics of patients with oral squamous cell carcinoma (OSCC). Serum and salivary samples were collected prior to and following the surgical treatment of 50 patients with OSCC. MIF concentrations were assessed by enzyme-linked immunosorbent assay and the adopted level of statistical significance was $\mathrm{P}<0.05$. The results revealed that serum MIF concentrations were significantly reduced following tumor resection in OSCC patients. Furthermore, higher preoperative salivary MIF concentrations were observed in patients with larger tumors and in those who succumbed to the disease. In conclusion, high salivary and serological MIF concentrations were identified in patients with OSCC. Nevertheless, only serological MIF concentrations may be considered as a potential marker for the early detection of OSCC recurrence once the salivary levels, prior and following treatment, do not show any significant differences.
\end{abstract}

\section{Introduction}

Oral squamous cell carcinoma (OSCC) is the most common type of cancer among head and neck neoplasms, and affects 275,000 individuals annually worldwide. In Brazil, the South

Correspondence to: Ms. Mariana Barbosa de Souza, Laboratory of Molecular Biology, Heliópolis Hospital, 276 Rua Conego Xavier, São Paulo 04231030, Brazil

E-mail: marianabarbosa@usp.br

Key words: oral cancer, inflammation, macrophage migration inhibitory factor, serum biomarker, salivary biomarker
American nation with the highest OSCC incidence, OSCC is the seventh most common type of cancer in the general population (1-3). Approximately $80 \%$ of OSCC cases are associated with tobacco and alcohol consumption; however, several other factors may also favor its development, including human papilloma virus infection and poor oral hygiene $(1,4,5)$.

Although the oral cavity may be easily examined, OSCC is often diagnosed late, which contributes to poor overall survival $(1,2)$. However, the identification of molecular biomarkers may improve existing clinical parameters for the development of novel diagnostic tools and treatment protocols, as well as aid in assessing prognosis (6). The identification of these biomarkers in the serum and saliva of OSCC patients is a promising and less invasive approach for the diagnosis, prognosis and assessment of disease status following therapy $(7,8)$.

It is known that cancer can have a significant inflammatory component and, in certain cases, inflammation itself may trigger a malignant transformation. In other cases, such as in OSCC, inflammation is caused and modulated by genetic and epigenetic alterations induced by carcinogens, including tobacco and alcohol. The modulation of the inflammatory response contributes to tumor progression by increasing malignant cell proliferation and survival, stimulating neoangiogenesis and reducing antitumor immunity and tumor responses to therapies (9-12).

Cytokines are important components of the inflammatory cancer-associated process. Additionally, tumor cells often overexpress cytokines in order to modulate their microenvironment, which therefore indicates a potential role for cytokines as biomarkers and therapeutic targets (12). Macrophage migration inhibitory factor (MIF) is a pro-inflammatory cytokine that regulates the innate immune response and has been shown to be important in various autoimmune diseases, in addition to being involved in cell proliferation, cell survival, migration and metastasis in cancer (13-19). In addition, previous studies have revealed that high serum MIF concentrations are observed in patients with colorectal, prostate, colon and gastric cancers, when compared with healthy subjects (20-23). High serum MIF concentrations in patients with prostate, gastric and hepatocellular cancer were found to be associated with a poor prognosis (24-26). 
In oral cancer, Kindt et al (27) demonstrated that, compared with normal tissues, MIF is overexpressed in tumors, indicating that this cytokine may contribute to tumor progression and the emergence of second primary tumors (27).

The aim of the present study was to assess the serum and saliva MIF concentrations in OSCC patients, prior to and following surgical treatment, and their correlation with clinicopathological characteristics. Serum and saliva MIF concentrations were also investigated as potential markers for disease control and recurrence in these patients.

\section{Materials and methods}

Study population. The study included 50 prospectively enrolled patients with primary OSCC who were treated at Heliópolis Hospital (Sao Paulo, Brazil) or the Padre Anchieta Teaching Hospital (Sao Paulo, Brazil) between 2011 and 2013. This study was approved by the ethics committees of Heliópolis Hospital, ABC Medical School (São Bernardo do Campo, Brazil) and the Medical School of the University of São Paulo (São Paulo, Brazil) and included only male patients with no history of autoimmune disease or prior cancer affecting any other anatomic areas, and to whom surgical treatment with or without postoperative radiotherapy and/or chemotherapy had been proposed. All patients provided written informed consent to participate. The clinicopathological characteristics of the patients are shown in Table I.

Patient samples. Prior to (0-30 days) and following (20 days to 3 months) surgery, $8-\mathrm{ml}$ whole blood samples and $5 \mathrm{ml}$ of total, non-stimulated saliva were collected from each patient. The collections were performed between 9 and 10am. The patients were advised not to eat, drink, smoke or use oral hygiene products for at least $2 \mathrm{~h}$ prior to collection. Blood samples and saliva were cooled during transportation and were immediately centrifuged for 15 and $20 \mathrm{~min}$, respectively, at $5031 \mathrm{x} \mathrm{g}$ and $4^{\circ} \mathrm{C}$. Next, $0.8 \mu \mathrm{l}$ of protease inhibitor cocktail (cat. no. P8340; Sigma-Aldrich, St. Louis, MO, USA) was added to each $400-\mu l$ aliquot of serum or saliva. The samples were then stored at $-80^{\circ} \mathrm{C}$ until enzyme-linked immunosorbent assay (ELISA) analysis was performed. When required for the study, the samples were thawed at room temperature $\left(18-25^{\circ} \mathrm{C}\right)$ and used immediately.

ELISA. The MIF concentrations in the serum and saliva samples were assessed using an ELISA kit (Quantikine, cat. no. DMF00B; R\&D Systems, Minneapolis, MN, USA) according to the manufacturer's instructions.

The optical densities were determined using a microplate reader (ELX800; BioTek Instruments, Inc., Winooski, VT, USA) at a wavelength of $450 \mathrm{~nm}$. To determine the standard curve, the original concentrations of various dilutions of recombinant human MIF were correlated with the corresponding optical densities.

The dilutions used for serum and saliva samples were 1:10 and 1:100, respectively. The samples exhibiting absorbances that were not included in the standard curve were diluted as required. The MIF concentrations in the samples were
Table I. Clinicopathological characteristics of patients with OSCC $(n=50)$.

\begin{tabular}{|c|c|}
\hline $\begin{array}{l}\text { Clinicopathological } \\
\text { characteristics }\end{array}$ & $\begin{array}{c}\text { OSCC frequency } \\
(\%)\end{array}$ \\
\hline \multicolumn{2}{|l|}{ Age (years) } \\
\hline Range & $40-88$ \\
\hline Median & 56.5 \\
\hline Mean (standard deviation) & $56.2(8.3)$ \\
\hline \multicolumn{2}{|l|}{ Ethnicity } \\
\hline Caucasian & $31(62.0)$ \\
\hline Non-caucasian & $16(32.0)$ \\
\hline Not available & $3(6.0)$ \\
\hline \multicolumn{2}{|l|}{ Smoking status } \\
\hline Current smoker & $42(84.0)$ \\
\hline Ex-smoker & $8(16.0)$ \\
\hline \multicolumn{2}{|l|}{ Alcohol consumption } \\
\hline Current drinker & $29(58.0)$ \\
\hline Ex-drinker & $20(40.0)$ \\
\hline Never & $1(2.0)$ \\
\hline \multicolumn{2}{|l|}{ Postoperative RT } \\
\hline Yes & $22(44.0)$ \\
\hline No & $28(56.0)$ \\
\hline \multicolumn{2}{|l|}{ Postoperative CT } \\
\hline Yes & $8(16.0)$ \\
\hline No & $42(84.0)$ \\
\hline \multicolumn{2}{|l|}{ pT stage } \\
\hline pT1-2 & $25(50.0)$ \\
\hline pT3-4 & $25(50.0)$ \\
\hline \multicolumn{2}{|l|}{$\mathrm{pN}$ stage } \\
\hline pNO & $30(60.0)$ \\
\hline $\mathrm{pN} 1-3$ & $20(40.0)$ \\
\hline \multicolumn{2}{|l|}{ Pathological staging } \\
\hline $\mathrm{I} / \mathrm{II}$ & $17(34.0)$ \\
\hline III/IV & $33(66.0)$ \\
\hline
\end{tabular}

RT, radiotherapy; CT, chemotherapy; OSCC, oral squamous cell carcinoma.

calculated according to the standard curve and presented as the mean of triplicates $(\mathrm{ng} / \mathrm{ml})$.

Statistical analysis. The Shapiro-Wilk test was used to assess the normally distributed MIF concentrations in the serum and saliva samples. MIF concentrations in the samples prior to and following surgery were compared using the Wilcoxon matched-pairs signed-ranks test. The nonparametric Mann-Whitney U test was used to assess the associations between variables with two categories relative to the MIF concentrations in the serum or saliva. The nonparametric Kruskal-Wallis test was used for variables with three categories. $\mathrm{P}<0.05$ was considered to indicate a statistically significant difference. STATA software, version 7.0 (StataCorp., College Station, TX, USA) was used to perform all statistical tests.

Novel indices were proposed for correlations with the quantity of tumor tissue. The lymph node index (LNI) was 
calculated as the sum of the number of metastatic lymph nodes and diameter $(\mathrm{cm})$ of the largest positive lymph node. The general index (GNI) was defined as the sum of the LNI and the largest diameter $(\mathrm{cm})$ of the primary tumor.

\section{Results}

MIF concentrations in serum and saliva samples prior to and following surgery. The results revealed that the MIF concentration was significantly decreased in the postoperative serum samples (Fig. 1). Confirming this result, a statistically significant decrease in serum MIF concentrations was identified following surgery when the data were stratified by disease status following treatment (Table II). However, no significant differences in MIF concentration were identified between the saliva samples collected prior to and following surgery (data not shown).

Associations between serum and saliva MIF concentrations and clinicopathological data. Correlations between the concentrations of MIF in serum and saliva, collected prior to and following surgical treatment, and clinicopathological data are shown in Table III.

The MIF concentrations in the preoperative saliva of patients was associated with tumor size; saliva concentrations were higher in patients with pT3 and pT4 stage tumors $(\mathrm{P}=0.001$; Table III) and in patients with tumors $>2.5 \mathrm{~cm}$ $(\mathrm{P}=0.020$; Table IV). Consequently, more advanced disease stage, stages III and IV $(\mathrm{P}=0.032$; Table III $)$, and a high GNI (0.025; Table IV) were associated with increased MIF concentrations in the saliva samples collected prior to tumor resection. Salivary MIF concentrations prior to surgery varied according to surgical margin involvement $(\mathrm{P}=0.045$; Table III).

In preoperative serum samples, the MIF concentrations were found to be significantly lower in patients with lymph node involvement $(\mathrm{P}=0.018$; Table III). However, when comparing the LNI, patients with an LNI $>3.5$ exhibited higher MIF concentrations in preoperative serum samples $(\mathrm{P}=0.025$; Table IV).

Table II shows that MIF concentrations in the preoperative saliva samples were higher in patients who succumbed to the disease than in surviving patients $(\mathrm{P}=0.023)$.

No significant associations were identified between the MIF concentrations in serum and saliva collected prior to surgery and perineural invasion, or tumoral inflammatory cell infiltration (Table III).

\section{Discussion}

MIF has been considered to present an important link between inflammation and cancer due to its pro-inflammatory role, overexpression in various tumor tissues and interactions with pathways that aid tumor progression. Its molecular mechanisms involve, among others, the inhibition of p53, extracellular-signal-regulated kinase/mitogen-activated protein kinase and $\mathrm{AKT} /$ protein kinase $\mathrm{B}$ activation, and sustained hypoxia-inducible factor $1-\alpha$ activation, all of which promote tumor cell proliferation, cell survival and tumor-associated neoangiogenesis (16,28-32). Under normal conditions, a variety of immune cells, as well as the pituitary

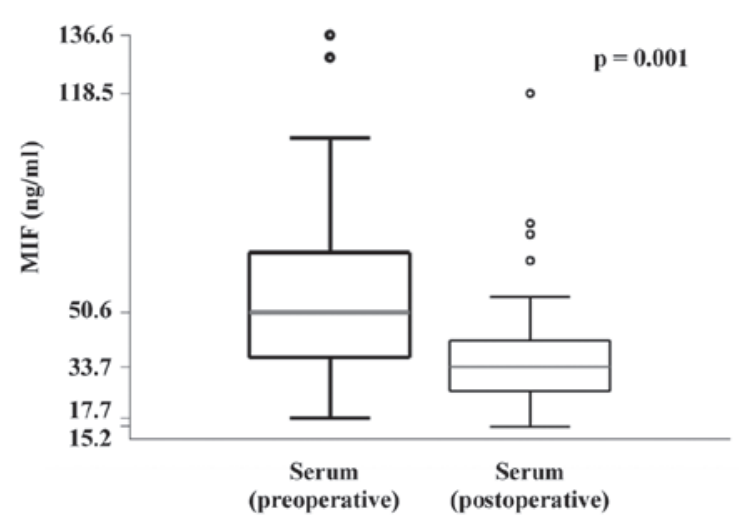

Figure 1. MIF concentrations in pre and post-operative serum samples of patients with oral squamous cell carcinoma. MIF, macrophage migration inhibitory factor.

gland and endothelial and epithelial cells of different organs, express MIF $(15,33)$. Several studies have identified MIF overexpression in tumors when compared with healthy tissues, and high MIF concentrations were detected in the serum of cancer patients when compared with healthy controls. Therefore, these data indicate a potential function for this protein as a biomarker of neoplastic diseases (20-22,34-40).

In the present study, in order to evaluate MIF as a serological and salivary biomarker of OSCC, MIF concentration in preand postoperative serum and saliva samples of patients with OSCC was investigated. To avoid interference of uncontrolled variables when comparing the MIF concentrations in different individuals, we used samples collected from the same patient following tumor resection as controls. Since MIF overexpression is also associated with autoimmune diseases (41-43), as well as with previously mentioned polymorphisms in the gene promoter of mif $(44,45)$, a comparison of samples of the same individual prior to and following tumor resection allowed control of these variables.

In this study, the serological MIF concentrations following tumor resection were significantly lower than those prior to tumor resection. This is consistent with the hypothesis that, since MIF is often overexpressed in tumors, it may also be detected at high levels in the serum of patients with OSCC. Considering the non-significant differences in MIF serological concentrations according to tumor size, this result indicates a possible function for MIF as a serological marker for OSCC detection, regardless of tumor extension. The serum MIF concentration was found to inversely correlate with lymph node involvement, in contrast to previous studies, which have reported that MIF induces the migration and invasion of tumor cells $(38,46-49)$. However, with regard to LNI, which may present the total metastatic lymph node mass, the serological MIF concentration was higher in individuals with a higher LNI. The LNI was calculated to compare the MIF concentrations in serum and saliva with more representative data regarding the total quantity of regional tumor present in the patient, since the number of metastatic lymph nodes or the diameter of the largest metastatic lymph node alone was not sufficient.

The dual and complex role of MIF has been discussed in detail. A study of patients with head and neck squamous cell carcinoma revealed correlations between low and high 


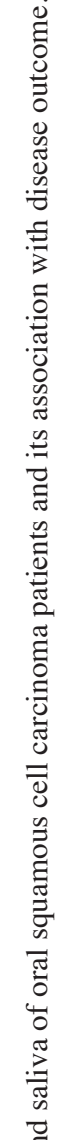

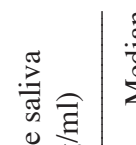

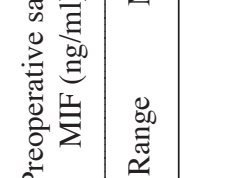

$m \simeq$

$\infty$

$\ddot{2}: \stackrel{0}{\circ}$

紊

눌

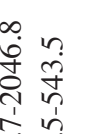

s.

\& in

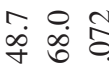

$\stackrel{\text { c. }}{\circ}:$

\&.

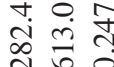

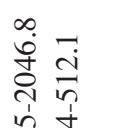

$n$
$n$
$n$
0
0
0
1
1

농

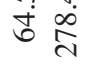

₹

\begin{tabular}{ll} 
वे & \multirow{2}{*}{} \\
0 & 0
\end{tabular}

$\begin{array}{ll}\overrightarrow{0} & 0 \\ 0 & 0 \\ 0 & 0 \\ 0 & 0\end{array}$

$m \sim$

도

ते

$\begin{array}{ll}n \\ n \\ n & \infty \\ n & 0 \\ 0 & 0 \\ 1 & 0 \\ 1 & 1 \\ 1 & 0\end{array}$

वें

离

ڤેं

$\begin{array}{ll}n & \infty \\ n & 0 \\ 0 & 0 \\ 0 & 0 \\ 1 & = \\ & n \\ & 0\end{array}$

शे

$\bar{m}+$

$\begin{array}{lll}4 & + \\ \infty & 0 & 0 \\ \infty & 0 & 0 \\ \infty & 0\end{array}$

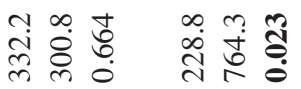

$\stackrel{n}{\circ} \stackrel{0}{0}$

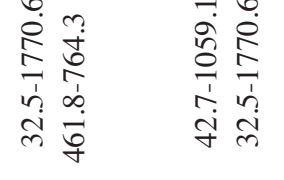

章

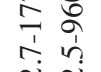

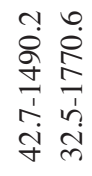

F⿻ @

ले

ina

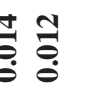

突

ธิ์ 픈

ิㅡㅇ 응

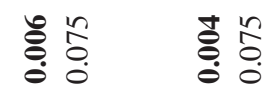

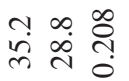

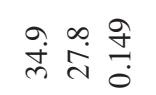

ले ले

in $\infty \begin{aligned} & \infty \\ & \text { in }\end{aligned}$

芦芦

है:

\begin{tabular}{lll}
$a$ & $\infty$ & 0 \\
$\dot{\vec{j}}$ & $\infty$ & \multicolumn{1}{c}{} \\
0
\end{tabular}

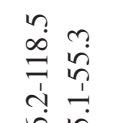

n?

$\infty n$

$n$

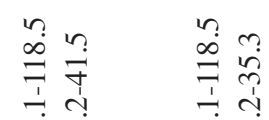

느

जั ते

ज.

त่

은

ำ

เ

i 으

तิ

\& N

$\underset{1}{ } \simeq$

ले

लै

군

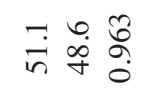

$\begin{array}{ll}\infty & 0 \\ a & 0 \\ \dot{q} & \stackrel{0}{1}\end{array}$

$\begin{array}{lll}n & n & \infty \\ n & \infty & \infty \\ n & 0\end{array}$

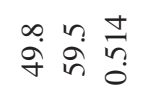

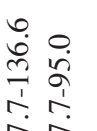

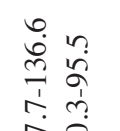

章

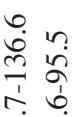

동

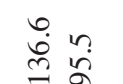

곤

든

\section{迥}

논

$\exists \sim$

$$
\text { m n }
$$

q 0

na

프

के

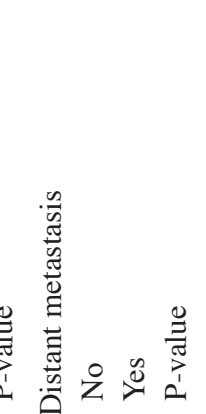

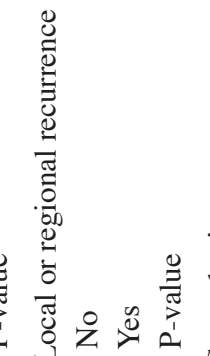

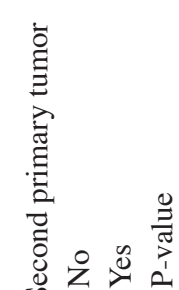

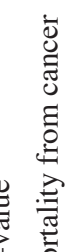

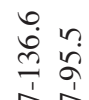

돋

चั 


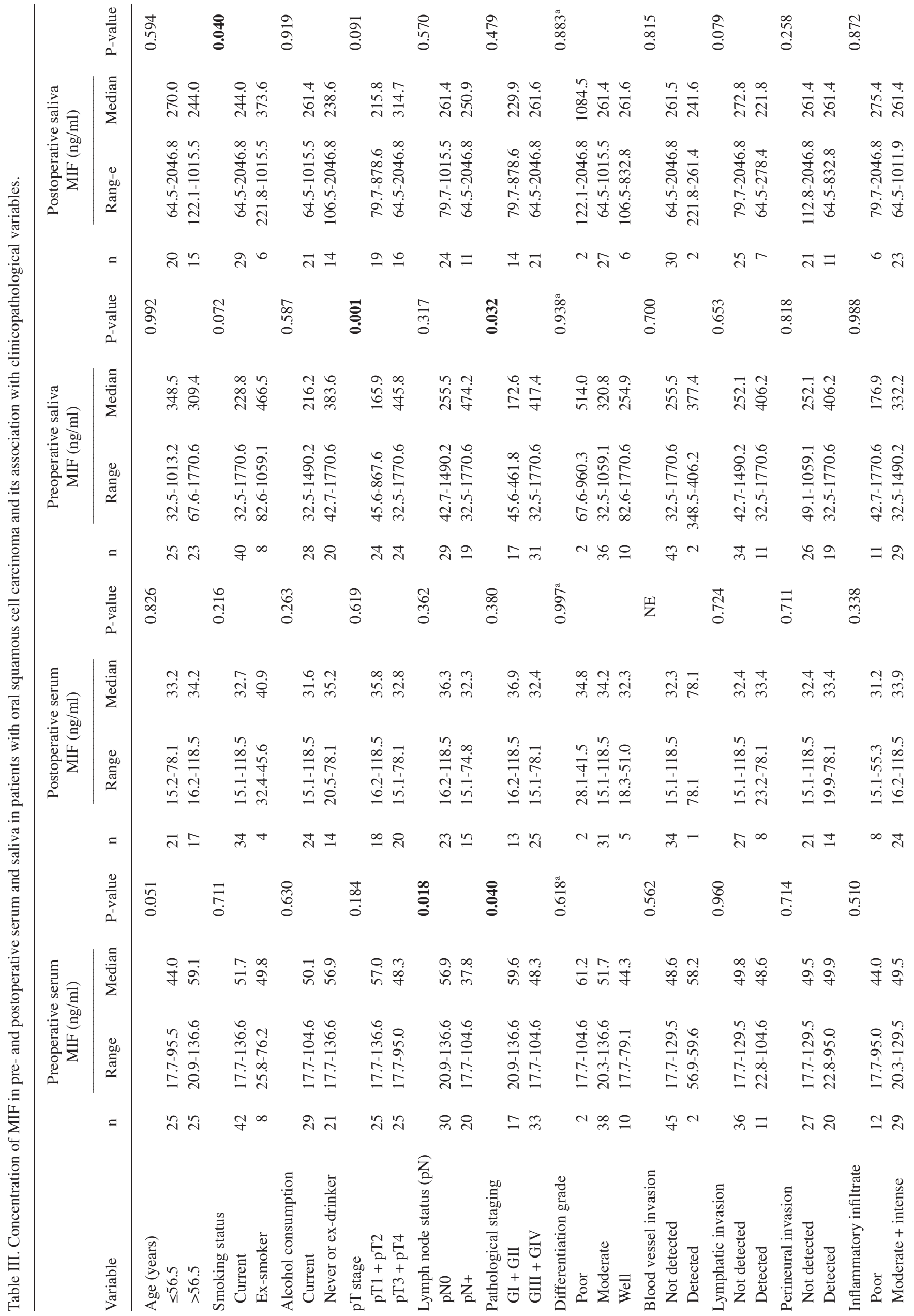


tumoral immunohistochemical expression of MIF and poor survival, and between moderate expression and improved survival (50). In addition, in the same study, high MIF expression in the tumor was positively associated with lymph node involvement, whereas low and moderate expression was found to correlate with no regional metastasis. Verjans et al (51) revealed that cytoplasmic MIF expression in tumor tissues was associated with improved survival in breast cancer patients, indicating that intracellular MIF may inhibit cell proliferation and indicate a favorable prognosis, whereas extracellular tumor tissue-derived MIF may be pro-inflammatory and may be associated with an unfavorable prognosis (51). These results demonstrate that the function of MIF in the progression and prognosis of several malignancies remains controversial, and further studies are required to investigate its different mechanisms of action, particularly with regard to its origin (from healthy tissues or tumors) and location within the cell. Accordingly, the current study group is also investigating MIF expression in tumor tissue and surgical margins.

To the best of our knowledge, the present study is the first to investigate MIF levels in saliva samples. It was observed that high levels of this protein are present in pre- and postoperative saliva of OSCC patients. Considering that OSCC cells secrete proteins that are eluted into the saliva, possibly via direct contact, it was hypothesized that salivary MIF concentration would decrease following tumor resection. However, this was not observed. We hypothesized that this result may be due to the constitutive expression of MIF by endocrine, immune, and particularly epithelial cells that are in direct contact with the external environment and regulate host responses to infections and stress. Pathogen-associated molecular patterns and inflammatory cytokines, including tumor necrosis factor- $\alpha$ and interferon- $\gamma$, are potential inducers of MIF secretion by macrophages, and the vast microbiota present in the oral cavity may facilitate this process, thus maintaining a high MIF concentration in the saliva (15). In addition, the inflammation triggered by the operative wound healing process may have increased the MIF concentrations in the saliva samples. However, an interval of 20-30 days following surgery was selected for sample collection, and longer periods were not considered as following this period the referred patients began radiotherapy and chemotherapy treatment, which may have interfered with the analysis. The salivary MIF concentrations were significantly higher in patients with larger tumors and those at more advanced pathological stages, than in patients with smaller tumors and those at initial pathological stages. On the basis of these results, we hypothesize that salivary MIF may not originate exclusively from OSCC cancer cells and, therefore, may not present a reliable marker for tumor diagnosis. MIF may also originate from endocrine, immune, and epithelial cells, and this may contribute to tumor progression via the aforementioned mechanisms. Regarding disease control status and prognosis evaluation, higher salivary MIF concentrations were identified in patients who succumbed to the disease than in those who survived. However, the limited follow-up period of this study was not long enough to comprehensively evaluate survival. This result indicates a possible role for MIF in the prognosis of patients with OSCC; 


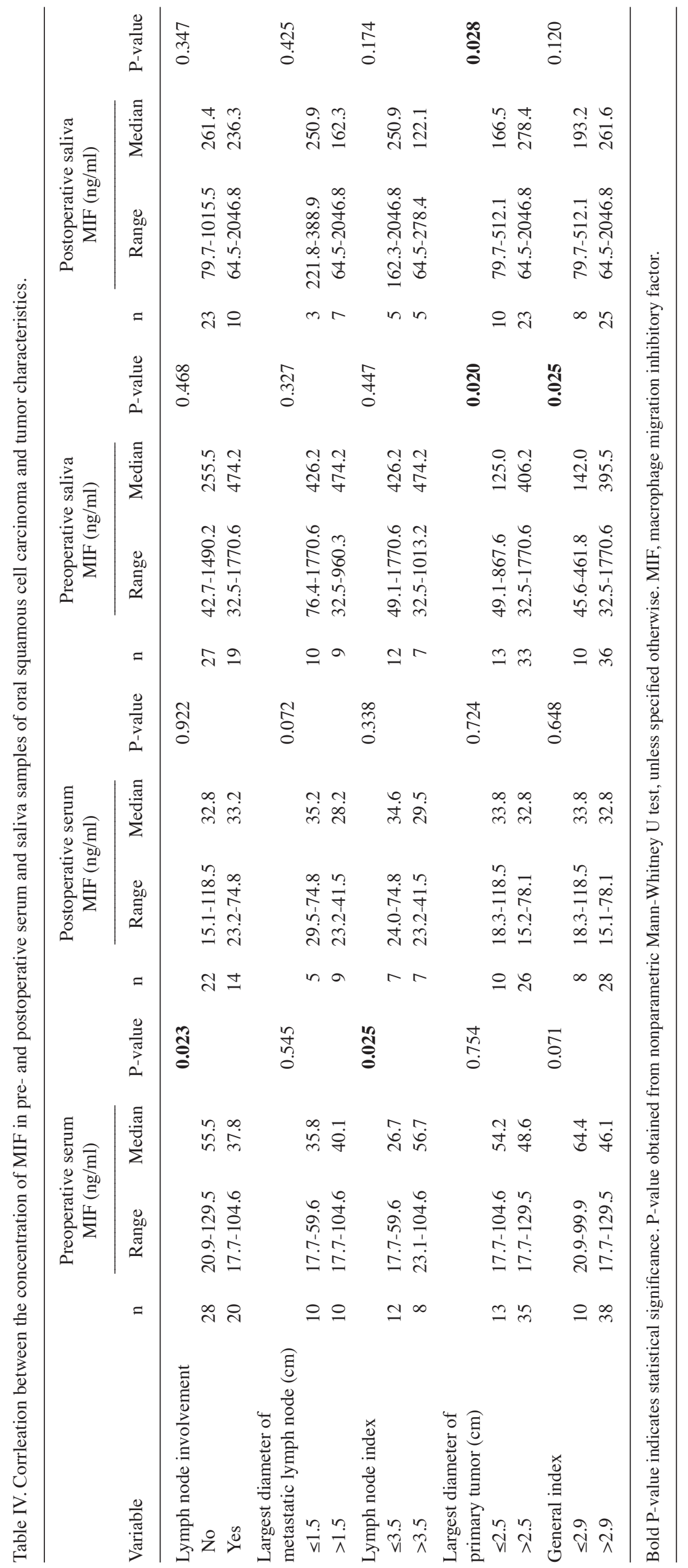


however, further studies are required to confirm this correlation.

As previously reported, MIF expression may be induced by epidermal growth factor (EGF) in breast cancer cells and also appears to be involved in the proliferative pathway activated by EGF (52). To date, the EGF receptor (EGFR) pathway is the most important pathway associated with OSCC development, and the investigation of the association between MIF and EGFR in OSCC may be extremely noteworthy. In addition, OSCC is an extremely heterogeneous disease; using MIF as a biomarker may be more useful when associated with other markers with known importance in OSCC development and prognosis, including other cytokines and proteins of the EGFR pathway.

In conclusion, the increased serological MIF concentrations in these patients prior to treatment observed in this study indicate a potential role for MIF as a biomarker for the early detection of OSCC recurrence. However, a long-term validation study is required, with a greater number of patients to evaluate serological MIF concentration in different disease statuses and during follow up or including MIF in a panel of markers.

\section{Acknowledgements}

The authors would like to thank the São Paulo Research Foundation (grant nos. FAPESP 2010/20765-3; and 2011/03281-5) and the Coordination of Improvement of Higher Level Personnel (CAPES) for financial support, the Head and Neck Genome Project (GENCAPO; www.gencapo.famerp.br) for scientific support and Miss. Karina Aparecida Meira da Silva and Mrs. Natalia Pita Magalhães for their assistance with sample collection.

\section{References}

1. Warnakulasuriya S: Global epidemiology of oral and oropharyngeal cancer. Oral Oncol 45: 309-316, 2009.

2. de Camargo Cancela M, Voti L, Guerra-Yi M, Chapuis F, Mazuir M and Curado MP: Oral cavity cancer in developed and in developing countries: population-based incidence. Head Neck 32: 357-367, 2010

3. INCA National Cancer Institute: Estimate/2012-Cancer Incidence in Brazil. Ministry of Health, Brasília, Brazil pp98, 2009.

4. Gillison ML: Current topics in the epidemiology of oral cavity and oropharyngeal cancers. Head Neck 29: 779-792, 2007.

5. Marques LA, Eluf-Neto J, Figueiredo RA, Góis-Filho JF, Kowalski LP, Carvalho MB, Abrahão M and Wünsch-Filho V: Oral health, hygiene practices and oral cancer. Rev Saude Publica 42: 471-479, 2008.

6. Palka KT, Slebos RJ and Chung CH: Update on molecular diagnostic tests in head and neck cancer. Semin Oncol 35: 198-210, 2008.

7. Hu S, Arellano M, Boontheung P, Wang J, Zhou H, Jiang J, Elashoff D, et al: Salivary proteomics for oral cancer biomarker discovery. Clin Cancer Res 14: 6246-6252, 2008.

8. Nagler RM: Saliva as a tool for oral cancer diagnosis and prognosis. Oral Oncol 45: 1006-1010, 2009.

9. Douglas WG, Tracy E, Tan D, Yu J, Hicks WL Jr, Rigual NR, Loree TR, et al: Development of head and neck squamous cell carcinoma is associated with altered cytokine responsiveness. Mol Cancer Res 2: 585-593, 2004.

10. Feller L, Altini M and Lemmer J: Inflammation in the context of oral cancer. Oral Oncol 49: 887-892, 2013.

11. Candido J and Hagemann T: Cancer-related inflammation. J Clin Immunol 33 (Suppl 1): S79-S84, 2013.

12. Mantovani A, Garlanda C and Allavena P: Molecular pathways and targets in cancer-related inflammation. Ann Med 42: 161-170, 2010.

13. Bloom BR and Bennett B: Mechanism of a reaction in vitro associated with delayed-type hypersensitivity. Science 153: 80-82, 1966.
14. David JR: Delayed hypersensitivity in vitro: its mediation by cell-free substances formed by lymphoid cell-antigen interaction. Proc Natl Acad Sci USA 56: 72-77, 1966.

15. Calandra T and Roger T: Macrophage migration inhibitory factor: a regulator of innate immunity. Nat Rev Immunol 3: 791-800, 2003.

16. Bucala R and Donnelly SC: Macrophage migration inhibitory factor: a probable link between inflammation and cancer. Immunity 26: 281-285, 2007.

17. Mitchell RA and Bucala R: Tumor growth-promoting properties of macrophage migration inhibitory factor (MIF). Semin Cancer Biol 10: 359-366, 2000.

18. Mitchell RA: Mechanisms and effectors of MIF-dependent promotion of tumourigenesis. Cell Signal 16: 13-19, 2004.

19. Grieb G, Merk M, Bernhagen J and Bucala R: Macrophage migration inhibitory factor (MIF): a promising biomarker. Drug News Perspect 23: 257-264, 2010.

20. Yasasever V, Camlica H, Duranyildiz D, Oguz H, Tas F and Dalay $\mathrm{N}$ : Macrophage migration inhibitory factor in cancer. Cancer Invest 25: 715-719, 2007

21. Muramaki M, Miyake H, Yamada Y and Hara I: Clinical utility of serum macrophage migration inhibitory factor in men with prostate cancer as a novel biomarker of detection and disease progression. Oncol Rep 15: 253-257, 2006.

22. Lee H, Rhee H, Kang HJ, et al: Macrophage migration inhibitory factor may be used as an early diagnostic marker in colorectal carcinomas. Am J Clin Pathol 129: 772-779, 2008.

23. He XX, Yang J, Ding YW, Liu W, Shen QY and Xia HH: Increased epithelial and serum expression of macrophage migration inhibitory factor (MIF) in gastric cancer: potential role of MIF in gastric carcinogenesis. Gut 55: 797-802, 2006.

24. Meyer-Siegler KL, Bellino MA and Tannenbaum M: Macrophage migration inhibitory factor evaluation compared with prostate specific antigen as a biomarker in patients with prostate carcinoma. Cancer 94: 1449-1456, 2002.

25. Hira E, Ono T, Dhar DK, El-Assal ON, Hishikawa Y, Yamanoi A and Nagasue N: Overexpression of macrophage migration inhibitory factor induces angiogenesis and deteriorates prognosis after radical resection for hepatocellular carcinoma. Cancer 103: 588-598, 2005.

26. Xia HH, Yang Y, Chu KM, Gu Q, Zhang YY,He H, Wong WM, et al: Serum macrophage migration-inhibitory factor as a diagnostic and prognostic biomarker for gastric cancer. Cancer 115: 5441-5449, 2009.

27. Kindt N, Lechien J, Decaestecker C, Rodriguez A, Chantrain G, Remmelink M, Laurent G, et al: Expression of macrophage migration-inhibitory factor is correlated with progression in oral cavity carcinomas. Anticancer Res 32: 4499-4505, 2012.

28. Hudson JD, Shoaibi MA, Maestro R, Carnero A, Hannon GJ and Beach DH: A proinflammatory cytokine inhibits p53 tumor suppressor activity. J Exp Med 190: 1375-1382, 1999.

29. Denz A,Pilarsky C, Muth D, Rückert F, Saeger HD and Grützmann R: Inhibition of MIF leads to cell cycle arrest and apoptosis in pancreatic cancer cells. J Surg Res 160: 29-34, 2010.

30. Li GQ, Xie J, Lei XY and Zhang L: Macrophage migration inhibitory factor regulates proliferation of gastric cancer cells via the PI3K/Akt pathway. World J Gastroenterol 15: 5541-5548, 2009.

31. Schrader J, Deuster O, Rinn B, Schulz M, Kautz A, Dodel R, Meyer $\mathrm{B}$, et al: Restoration of contact inhibition in human glioblastoma cell lines after MIF knockdown. BMC Cancer 9: 464, 2009.

32. Rendon BE, Willer SS, Zundel W and Mitchell RA: Mechanisms of macrophage migration inhibitory factor (MIF)-dependent tumor microenvironmental adaptation. Exp Mol Pathol 86: 180-185, 2009.

33. Calandra T, Bernhagen JL, Mitchell RA and Bucala R: The macrophage is an important and previously unrecognized source of macrophage migration inhibitory factor. J Exp Med 179: 1895-1902, 1994.

34. Camlica H, Duranyildiz D, Oguz H, Oral EN and Yasasever V: The diagnostic value of macrophage migration inhibitory factor (MIF) in gastric cancer. Pathol Oncol Res 14: 79-83, 2008.

35. Fang W, Li X, Jiang Q, Liu Z, Yang H, Wang S, Xie S, et al: Transcriptional patterns, biomarkers and pathways characterizing nasopharyngeal carcinoma of Southern China. J Transl Med 6: 32, 2008.

36. Kamimura A, Kamachi M, Nishihira J, Ogura S, Isobe $H$, Dosaka-Akita H, Ogata A, et al: Intracellular distribution of macrophage migration inhibitory factor predicts the prognosis of patients with adenocarcinoma of the lung. Cancer 89: 334-341, 2000.

37. Mohri Y, Mohri T, Wei W, Qi YJ, Martin A, Miki C, Kusunoki M, et al: Identification of macrophage migration inhibitory factor and human neutrophil peptides 1-3 as potential biomarkers for gastric cancer. Br J Cancer 101: 295-302, 2009. 
38. Ren Y, Law S, Huang X, Lee PY, Bacher M, Srivastava G and Wong J: Macrophage migration inhibitory factor stimulates angiogenic factor expression and correlates with differentiation and lymph node status in patients with esophageal squamous cell carcinoma. Ann Surg 242: 55-63, 2005.

39. Tomiyasu M, Yoshino I, Suemitsu R, Okamoto T and Sugimachi K: Quantification of macrophage migration inhibitory factor mRNA expression in non-small cell lung cancer tissues and its clinical significance. Clin Cancer Res 8: 3755-3760, 2002

40. Xia HH, Zhang ST, Lam SK, Lin MC, Kung HF and Wong BC: Expression of macrophage migration inhibitory factor in esophageal squamous cell carcinoma and effects of bile acids and NSAIDs. Carcinogenesis 26: 11-15, 2005.

41. Cooke G, Armstrong ME and Donnelly SC: Macrophage migration inhibitory factor (MIF), enzymatic activity and the inflammatory response. Biofactors 35: 165-168, 2009.

42. Sanchez-Zamora Y, Terrazas LI, Vilches-Flores A, et al: Macrophage migration inhibitory factor is a therapeutic target in treatment of non-insulin-dependent diabetes mellitus. FASEB J 24: 2583-2590, 2010.

43. Bucala R (ed). MIF Rediscovered. In: MIF, A Most Interesting Factor. World Scientific Press, London, 2007.

44. Baugh JA, Chitni S, Donnelly SC, et al: A functional promoter polymorphism in the macrophage migration inhibitory factor (MIF) gene associated with disease severity in rheumatoid arthritis. Genes Immun 3: 170-176, 2002.

45. Donn RP, Shelley E, Ollier WE, et al: A novel 5'-flanking region polymorphism of macrophage migration inhibitory factor is associated with systemic-onset juvenile idiopathic arthritis. Arthritis Rheum 44: 1782-1785, 2001.

46. Sun B, Nishihira J, Yoshiki T, et al: Macrophage migration inhibitory factor promotes tumor Invasion and metastasis via the Rho-dependent pathway. Clin Cancer Res 11: 1050-1058, 2005.
47. Funamizu N, Hu C, Lacy C, Schetter A, Zhang G, He P, et al: Macrophage migration inhibitory factor (MIF) induces epithelial to mesenchymal transition, enhances tumor aggressiveness and predicts clinical outcome in resected pancreatic ductal adenocarcinoma. Int J Cancer: Jul 23, 2013 (Epub ahead of print).

48. Han I, Lee MR, Nam KW, Oh JH, Moon KC asnd Kim HS: Expression of macrophage migration inhibitory factor relates to survival in high-grade osteosarcoma. Clin Orthop Relat Res 466: 2107-2113, 2008.

49. Liu H, Chen G, Zhang W, et al: Overexpression of macrophage migration inhibitory factor in adenoid cystic carcinoma: correlation with enhanced metastatic potential. J Cancer Res Clin Oncol 139: 287-295, 2013.

50. Suzuki F, Nakamaru Y, Oridate N, Homma A, Nagahashi T, Yamaguchi S, Nishihira J, et al: Prognostic significance of cytoplasmic macrophage migration inhibitory factor expression in patients with squamous cell carcinoma of the head and neck treated with concurrent chemoradiotherapy. Oncol Rep 13: 59-64, 2005.

51. Verjans E, Noetzel E, Bektas N, Schütz AK, Lue H, Lennartz B, Hartmann A, et al: Dual role of macrophage migration inhibitory factor (MIF) in human breast cancer. BMC Cancer 9: 230, 2009.

52. Lim S, Choong LY, Kuan CP, Yunhao C and Lim YP: Regulation of macrophage inhibitory factor (MIF) by epidermal growth factor receptor (EGFR) in the MCF10AT model of breast cancer progression. J Proteome Res 8: 4062-4076, 2009. 